\section{Increase in quinine tolerance with incremental training*}

\author{
JAY PETERS, PAUL T. P. WONG†, and KENNETH L. TRAUPMANN \\ University of Texas at Austin, Austin, Tex. 78712
}

When hungry rats were given quinine-adulterated food pellets, it was found that the quinine tolerance level could be raised if quinine concentration was increased gradully and that, with more minute increments, the tolerance could be further increased.

Previous investigations have shown that the tolerance level for aversive stimulation can be raised by presenting the stimulus initially at some low level and by increasing its intensity gradually over several test trials. Thus, Miller (1960) demonstrated that rats given an incremental sequence of shock intensities continued to run to shock that was intense enough to inhibit running in constant-intenseshock controls. Working with curarized dogs, Church, LoLordo, Overmier, Solomon, \& Turner (1966) found that providing a gradually increasing series of electrical shocks reduced the magnitude of cardiac acceleration to intense shock below that of either previously unshocked Ss or Ss exposed to a similar number of full-intensity shocks. Finally, Davis \& Wagner (1969) found that 750 exposures to tones, gradually increased from 83 to $118 \mathrm{~dB}$ in $2.5-\mathrm{dB}$ steps, produced much greater habituation of the startle response in rats to subsequent $120-\mathrm{dB}$ tones than did 750 exposures to the $120-\mathrm{dB}$ tone itself. Taken together, these findings strongly suggest that the gradual introduction of an aversive stimulus may be an especially efficient habituation procedure. The following study was designed to test whether or not presentation of an incremental sequence of quinine-adulterated food to hungry rats would raise the tolerance level for quinine when compared to a nonincremental control.

\section{METHOD}

Fifteen male albino rats, obtained from Holtzman Farms, Madison, Wisconsin, were housed in individual

*The research was supported by NSF Grant G B-14990X to Abram Amsel.

t Requests for reprints should be addressed to Paul T. P. Wong, Department of Psychology, York University, Downsview, Ont., Canada. cages and maintained on a 12-g food-deprivation schedule, with ad lib water starting 4 . weeks before the experiment and continuing throughout the experimental period. The Ss were divided into two groups: 10 experimentals and 5 controls.

Several stock concentrations of quinine hydrochloride $\left(\mathrm{C}_{20} \mathrm{H}_{2}{ }_{4} \mathrm{~N}_{2} \mathrm{O}_{2}\right.$ - $\left.\mathrm{HCL} \cdot 2 \mathrm{H}_{2} \mathrm{O}\right)$ were prepared, starting from $.394 \mathrm{M}$ with $.006 \mathrm{M}$ increments between concentrations. Once the highest quinine tolerance level was additional quinine solutions over and above the highest tolerance level were prepared with $.001 \mathrm{M}$ increments between solutions. Sufficient numbers of $300-\mathrm{mg}$ Noyes pellets were soaked in the various solutions for $60 \mathrm{sec}$ and allowed to dry in containers for at least $24 \mathrm{~h}$ before testing.

During testing, the experimental Ss were placed in an $8 \times 12 \times 8$ in. aluminum box with a Plexiglas top containing the quinine pellet. The Ss were given one pellet per day and were allowed $3 \mathrm{~min}$ to consume it. Experimental Ss were required to consume a pellet successfully on four successive trials before a pellet of the next higher concentration was presented. The first trial was with a $.394 \mathrm{M}$ pellet. The highest quinine tolerance level was considered to be reached when $S$ failed to eat within the 3-min period on any one of the four trials. One control $S$ was given a pellet of the highest concentration reached by all the experimentals. If the pellet was refused, this $S$ and another control $S$ were given a pellet of the next lower concentration. In this manner, the highest acceptable concentration was determined for the control Ss.

Subsequently, the experimental Ss were given another series of trials of above the previously established determined for each experiment $S$, increasing concentrations over and highest tolerance level. This time, the increment was .001M instead of $.006 \mathrm{M}$. This follow-up test was to see if, with more minute increments, these Ss could accept the level of concentration which they previously rejected. During this phase, the criterion was the same as during the earlier phase of incremental training.

RESULTS AND DISCUSSION

During the first series of incremental training, two experimental Ss accepted the quinine-adulterated pellets which were soaked in the $.442 \mathrm{M}$ concentration, while the rest consumed pellets soaked in the $.448 \mathrm{M}$ concentration. During the subsequent series of incremental training, 9 out of the $10 \mathrm{Ss}$ accepted the level of concentration which they previously rejected. That is, of the two Ss which rejected pellets soaked in the $.448 \mathrm{M}$ concentration, one $S$ accepted the $.447 \mathrm{M}$ and one the .448M concentration. The remaining 8 Ss now accepted pellets soaked in the $.454 \mathrm{M}$ concentration which was previously rejected with $.006 \mathrm{M}$ increments. With regard to the controls, while one accepted pellets soaked in the $.424 \mathrm{M}$ concentration, the remaining $S s$ accepted only the pellets soaked in the $.406 \mathrm{M}$ concentration. Thus, all experimental Ss were able to tolerate quinine concentrations that exceeded the highest concentration acceptable by any of the control Ss.

The present findings clearly demonstrate that the quinine tolerance level can be raised with incremental habituation training and that, with more minute increments, the tolerance can be increased further. These results thus extend those previous findings on the increased tolerance to aversive stimulation produced by an incremental procedure of habituation training.

\section{REFERENCES}

CHURCH R $M$ LOLORDO V OVERMIER, J. B., SOLOMON, R. L., \& TURNER, L. H. Habituation due to incremental increase in electrical shock intensities. Journal of Comparative \& Physiological Psychology, 1966,62, 1-8. DAVIS, M., \& WAGNER, A. R. Habituation of startle response due to incremental increase of tone intensity. Journal of Comparative \& Physiological Psychology, $1969,67,448-492$.

MILLER, N. E. Incremental training to resist stresses such as pain and fear. Journal of Comparative \& Physiologica Psychology, 1960,53,59-62. 